\title{
Gender Dimensions in UGC and VGI: A Desk-Based Study
}

\author{
Renate STEINMANN ${ }^{1}$, Elisabeth HÄUSLER ${ }^{1}$, Silvia KLETTNER ${ }^{2}$, \\ Manuela SCHMIDT ${ }^{2}$ and Yuwei LIN ${ }^{3}$ \\ ${ }^{1}$ Salzburg Research, Salzburg/Austria·renate.steinmann@salzburgresearch.at \\ ${ }^{2}$ Technical University of Vienna/Austria \\ ${ }^{2}$ University of Salford/United Kingdom
}

This contribution was double-blind reviewed as full paper.

\begin{abstract}
Much user generated content (UGC) is produced or reproduced by volunteers. Many UGC platforms exist nowadays to facilitate the process of co-production. The majority of them, however, show a gender imbalance of their contributors' communities, including platforms for collecting Volunteered Geographic Information (VGI). Causes of this gender imbalance have not yet been elaborated sufficiently. In order to identify some of these factors which influence women's participation in UGC platforms, case studies were carried out to compare different spatially explicit, spatially implicit, and non-spatial UGC projects. The case study analysis is based on a conceptual framework used to analyse participants' motivations for contributing VGI in reference to gender. The findings suggest several criteria related to the imbalance of female and male contributors in the field of VGI.
\end{abstract}

\section{Introduction}

The interest for creating digital spatial data and maps, individually and collectively, has been increasing in the last years. Some terms have been created to describe this phenomenon including vernacular mapping (GERLACH 2010), citizen cartography, amateur cartography, Public Participation Geographic Information Systems (PPGIS) and Volunteered Geographic Information. We have chosen to use Volunteered Geographic Information (VGI) in this work to emphasise the volunteering aspect of geographic data collection and distribution by volunteers using the internet (RAK, COLEMAN \& NICHOLS 2010). The term was first defined by GOODCHILD (2007: 212) as a "special case of user-generated content (UGC) and [...] the harnessing of tools to create, assemble, and disseminate geographic data provided voluntarily by individuals". ELWOOD, GOODCHILD \& SUI (2012: 574) further define VGI as "that subset of user-generated content that concerns the characterization of the geographic domain". In addition, HAKLAY, BUDHATHOKI \& ANTONIOU (2010) propose a further VGI classification of this "special case/subset" of UGC by introducing the terms spatially explicit, spatially implicit and non-spatial UGC. In the context of explicit spatial UGC the authors address projects which allow editing geographic features such as lines, points or polygons. Furthermore, while recent works (e.g. BRANDO \& BUCHER 2010) define spatial content as any content with a spatial dimension, the above authors limit the defini- 
tion of spatially implicit UGC to information which is bound to a place (e.g. taking a photograph and publishing it on the web or sharing local information like on the platform Foursquare). This draws a clear boundary between spatial and non-spatial UGC, which is defined as content which can be "collaborate, update and keep in touch regardless of where you are" (HAKLAY et al. 2010: 5).

A common characteristic of UGC, independent of the type, is that its information is collectively contributed by a heterogeneous crowd of people who participate voluntarily (REHRL, GRÖCHENIG, HOCHMAIR, LEITINGER, STEINMANN \& WAGNER 2012). However, existing research has suggested that women are not contributing information and creating content at the same rate as men (STEPHENS \& RONDINONE 2012). While studies on the use of social UGC platforms such as Facebook have indicated that women are equally represented and may be even more active users than men (e.g. STEPHENS \& RONDINONE 2012), research on spatially explicit UGC projects has demonstrated that men are the dominant players (e.g. BudHATHOKI, Nedović-BUdić \& BRUCE 2010). However, research on the exploring factors which influence this phenomenon of relatively lower female participation rates especially in VGI projects is still missing.

\section{Contribution}

Our work seeks to explore more carefully criteria that influence gender imbalance among VGI contributors. To this end, we extend existing research by analysing similarities and differences between spatial and non-spatial UGC platforms in a cross-case analysis (user structure, motivational factors, contribution mechanism, and communication behaviour). Based on our main research questions "Why are there fewer women in the field of VGI than men and what are the main factors for this development?" the following research questions will be addressed in this work:

- Is gender participation imbalance a phenomenon of UGC in general or is the spatial aspect a critical point for participation/non-participation?

- Which criteria influence gender participation imbalance in spatially explicit, implicit and non-spatial UGC projects?

The remainder of the paper is structured as follows: section two introduces related work on gender participation imbalance in spatially explicit UGC platforms. Section three describes the case study methodology and introduces the selected cases. Section four presents the outcome of our cross-case analysis. Finally, section five discusses the results and offers some thoughts on the implications for future research.

\section{Related Work}

In the discussion of related work we focus on (qualitative) studies regarding gender participation inequality (in terms of sex) in spatially explicit UGC projects. Currently, the main research strand analysing this phenomenon focuses on demographic facts as is reflected in various studies. For instance, according to STARK (2010), the typical OpenStreetMap (OSM) contributor is male, above-average educated and belongs to the age groups 24 to 27 or 27 to 45 years. They are technologically enthusiastic, got to know OSM over the Internet 
and perceive participating in the OSM community as meaningful spare time activity. Additionally, HAKLAY \& BUDHATHOKI (2010) found that the number of actively contributing women is just about $3 \%$ at the time when the survey was carried out. In a study on the OSM community conducted by LECHNER (2011), just 1.8\% of the 225 participants were females. In addition to demographic facts, motivational factors for contributing geographic information have also been analysed, in general (COLEMAN, GEOGIADOU \& LABONTE 2009; BudHATHOKI et al. 2010). In detail, StePHENS \& RondinONE (2012) studied differences between the motivations of women and men in contributing geographic information. Findings of the authors' survey ( $\mathrm{n}=1175,557$ male, 548 women, 70 other) reveal that women are volunteering non-geographic social information on the Internet but not intentionally volunteering geographic information even within a social context. Furthermore, authors conclude that men are the primary constructors of the world view that is represented by VGI. However, we are not aware of further gender-specific studies in this research area analysing reasons for the relatively low female participation in the field of VGI, in depth.

\section{Methodology}

For our exploratory research we applied a case study approach of purposive sampling (DEVERS \& FRANKEL 2000). Case studies allow considering a variety of variables which are of interest, as well as multiple data sources. Purposive sampling distinguishes between three types of cases which have the greatest payoff: a) typical cases (i.e. cases which are normal/average for those being studied), b) extreme cases (i.e. cases who represent unusual manifestations of the phenomenon of interest or c) negative cases (i.e. cases which are "exceptions to the rule"). In our work we chose typical cases in order to get a broad and neutral picture of the most prominent UGC projects.

\subsection{Selected cases}

We selected UGC projects according to the classification of spatially explicit, spatially implicit, and non-spatial projects, proposed by HAKLAY and colleagues (2010). OpenStreetMap (OSM) and Google Map Maker (GMM) were selected as case studies for analysing explicit spatial UGC projects. Currently, OSM can be considered the most famous spatially explicit UGC project. It provides free geographic data of the whole world, collected and edited voluntarily by mappers. According to statistics, the project recorded about one million registered users by January 2013. Furthermore, due to its similarity to OSM, GMM was chosen for analysis, too. The project was started by Google in 2008 with the intention to expand Google Maps. However, it does not provide programmatic access to the collected data. Thus, Google itself but not the community of about 25.000 people owns the data. For spatially implicit projects, Foursquare (FSQ) and Panoramio (PAN) serve as cases for further analyses. FSQ is a location-based social networking site which enables users to get into contact with friends who are locally nearby. FSQ was chosen for analysis due to its popularity (20 million users). PAN, which is owned by Google, is a website for sharing place-related photos. As second spatially implicit UGC project, PAN records about 4.7 million registered users. Lastly, the platforms Wikipedia (WP) and Facebook (FB) are taken to represent non-spatial UGC projects for our case study analysis. 
As a structural basis for analysing our cases we applied the three-tiered conceptual framework proposed by BUDHATHOKI and colleagues (2010) (see next section). This framework was primarily designed for understanding VGI issues such as the motivation to contribute geographic information online, but by virtue of its neutral structure, it can also be used for non-spatial UGC projects. The data source for each case study is derived from a literature review. Additionally for the case of GMM and PAN, we contacted the responsible programme managers and GIS specialist at Google in order to gain missing information on the project. We then identified patterns across the selected case studies. Results of the crosscase study analysis are presented below.

\subsection{Criteria for evaluating UGC projects}

As shown in Figure 1 the framework is composed of three so-called arenas: (1) Motivation, (2) Action and Interaction, and (3) Outcome, which are further divided into sub-arenas. In the following, we will introduce each sub-arena and corresponding criteria selected for analysing our cases.

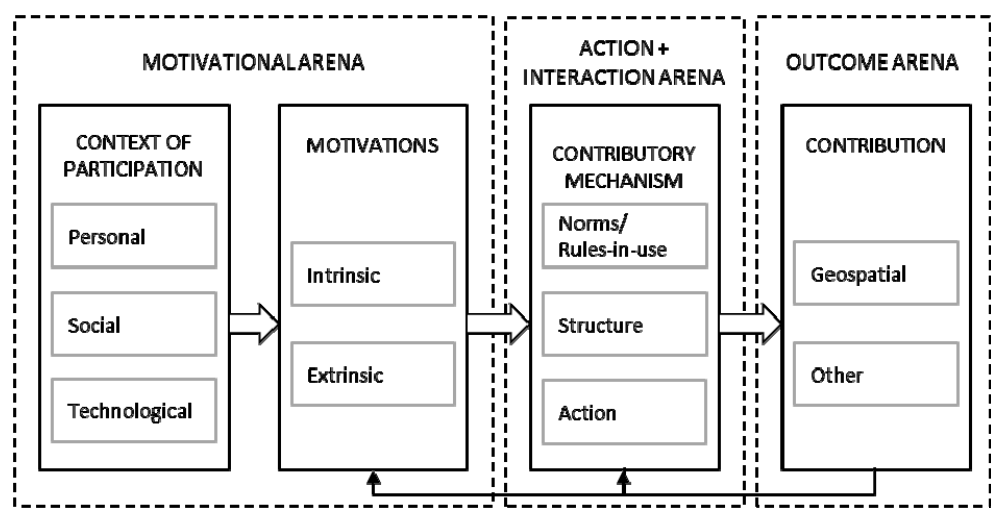

Fig. 1: Conceptual framework for evaluating UGC projects (according to Budhathoki et al. 2010)

Motivational Arena: According to the definition of BUDHATHOKI and colleagues (2010), intrinsic and extrinsic motivations arise from one's context of participation which can be classified into personal, social and technological factors. In our analysis we will focus on contextual factors of UGC contributors: gender, age and education. We will also examine platform-related intrinsic and extrinsic motives.

Action and Interaction Arena: Criteria in the action and interaction arena address the processes of decision-making and contributing data to a project. It defines how people interact and cooperate and how different norms, processes, and structures affect such decisions. The action and interaction arena is divided into three sub-arenas: (1) Norms/Rules-in-use (normative understandings within the community), (2) Structure (result of applying the rules), and (3) Action (users' actual decisions to contribute within the constraints of the structure). For our analysis, we will consider criteria from all three sub-arenas such as management of rules, data contribution mechanism and software as well as communication tools. 
Outcome Arena: The outcome arena deals with the kind of contribution made by volunteers. For analysis, we selected the platforms according to the type of contributions users make (non-spatial UGC platforms, spatially implicit UGC platforms and spatially explicit UGC platforms). Furthermore, in our analysis, we examine which information contributors primarily share within the different platforms.

\section{Cross-Case Study Analysis}

In the cross-case study analysis, the six case studies (two for each of the categories nonspatial, spatially implicit and spatially explicit UGC projects) were analysed according to similarities and differences.

\subsection{Context of participation}

For collecting data on the participants' gender we firstly took existing literature into account. Furthermore, we contacted Google to get user profile information of GMM and PAN users as there is no data available for both platforms. However, according to company policies no information was handed out. Thus, although we are aware of the limitations of this method (mainly because users may not reveal their true identity online), we chose the approach of manually analysing profile pages of GMM and PAN in order to identify users' sex based on their names and photos provided online. In case of GMM we analysed profiles of the discussion forum (GMM discussion forum) from the section "General mapping", filter: 29 April to September 2012. Male and female users (altogether 108 users) were identified either by profile photo or by user names. Analysis results show (see Fig. 2) that about $2 \%$ of GMM users are female. For PAN, profile photos were analysed (section "Suggestions and Support") from 13 September to 21 September 2012. Male and female users were identified on the basis of available photos. The results of 200 users show $12 \%$ females and $88 \%$ males. Furthermore, according to statistics from the website check Facebook, women are especially present in FB (53\%) and FSQ (60\%) (IGNITE SOCIAL MEDIA 2011), followed by PAN (12\%), WP (9\%) (WIKIPEDIA EDITORS STUDY 2011), and with lowest participation rates in OSM (3\%) (HAKLAY \& BUDHATHOKI 2010) and GMM (2\%). The spatially explicit UGC platforms (OSM and GMM) show the lowest proportions of female participants.

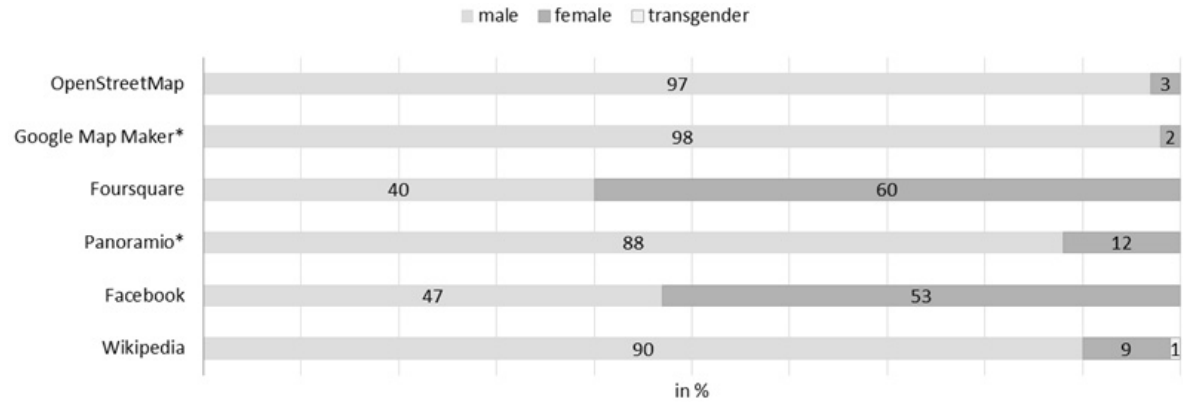

Fig. 2: UGC platforms - male and female users in \%; * Data based on own enquiry (see chapter 4.1) 
Results on the age of users suggest similarities between WP and OSM users. Young and computer savvy men are the largest group of users: within OSM $30 \%$ of users are between 20 and 30 years old; similar to the typical WP editor of 30 years of age (WIKIPEDIA EDITORS STUDY 2011). Regarding FB, the majority of users (52\%) are between 18 and 34 years old. $70 \%$ of FSQ users are between 25 and 44 of age. To summarize, the age of the typical UGC user is rather low for all platforms. Especially FB, OSM and WP have a user structure which is very young of age. However, again there is no data available about the age of users of GMM and PAN.

Comparing the platforms regarding education, 61\% of WP editors (WIKIPEDIA EDITORS STUDY 2011) have either a Bachelor's, associate or higher/post-graduate degree. For OSM the percentage of users with a university degree is even higher (78\%) (BUDHATHOKI et al. 2010 ). Only $30 \%$ of FSQ users and $24 \%$ of FB users have a university degree. This reflects that the majority of OSM and WP users are highly educated. Furthermore, WP, OSM and FSQ have in common that by trend computer savvy persons take part in the community (VALENTINO-DEVRIES 2011). Fifty per cent of OSM users have a GIS background, 70\% of OSM users also contribute to WP and $60 \%$ of OSM users contribute to other open-source projects despite OSM. However, for the other platforms selected for the case study analysis, no data on the participants' skill levels is available.

\subsection{Motivations}

Motives were examined for each case study individually from various sources of literature: OSM (RAMM \& TOPF 2010; UhlMANn, TOMMASINI \& STARK 2010; NedOVIĆ-Budić \& BudHATHOKI 2010; COLEMAN et al. 2009), GMM (Boulton 2010), FSQ (Foursquare website), PAN (PAN website, PAN article on Wikipedia), FB (Ross, OrR, ARSENEAUlt, SIMMERING \& ORR 2009), and WP (GlOTT, SCHMIDT \& GOSH 2010; YANG \& LAI 2010, Nov 2007). Table 1 depicts the findings of similarities and differences of each of the six UGC platforms examined.

Based on the results of Table 1, OSM and GMM show similar motives of learning and intellectual stimulation, self-expression, editing data as fun activity, recreation, and altruism. However, in both of these spatially explicit UGC projects the social aspect as motive for participating is missing. Comparing the two spatially explicit projects OSM and GMM with the non-spatial project WP, similar patterns (aside from the usage of new technologies present in OSM and GMM) can be found. Social motives appear to be rather irrelevant when people use GMM, OSM or WP, whereas this is the main motive for people participating in FB and FSQ. A motive for all analysed platforms is the aspect of selfrepresentation, e.g. in front of friends. Furthermore, the altruistic motivation of volunteering to share knowledge, information etc. is also mentioned within all platforms and seems to be a key motivation for participating in UGC projects. To be motivated by career opportunities is especially important by the community members of OSM, GMM, FSQ, FB, and WP. 
Table 1: Motives for participating in UGC platforms

(Source: after literature noted in first paragraph of this section)

\begin{tabular}{|c|c|c|c|c|c|c|}
\hline & \multicolumn{2}{|c|}{$\begin{array}{l}\text { spatially explicit } \\
\text { UGC }\end{array}$} & \multicolumn{2}{|c|}{$\begin{array}{l}\text { spatially implicit } \\
\text { UGC }\end{array}$} & \multicolumn{2}{|c|}{$\begin{array}{l}\text { non-spatial } \\
\text { UGC }\end{array}$} \\
\hline & OSM & GMM & FSQ & PAN & FB & WP \\
\hline \multicolumn{7}{|l|}{ Intrinsic MOTIVES } \\
\hline Self-expression / self-image & $\mathrm{x}$ & $\mathrm{x}$ & $\mathrm{x}$ & $\mathrm{x}$ & $\mathrm{x}$ & $\mathrm{x}$ \\
\hline $\begin{array}{l}\text { Altruism - contributors seek to benefit } \\
\text { others }\end{array}$ & $x$ & $x$ & $x$ & $x$ & $x$ & $x$ \\
\hline Editing data is fun & $\mathrm{x}$ & $\mathrm{x}$ & & & & $\mathrm{x}$ \\
\hline $\begin{array}{l}\text { Recreation - Contributors sometimes need } \\
\text { to go outdoors to collect content }\end{array}$ & $x$ & $\mathrm{x}$ & & $\mathrm{x}$ & & \\
\hline $\begin{array}{l}\text { Learning and intellectual stimulation, } \\
\text { usage of new technologies }\end{array}$ & $\mathrm{x}$ & $\mathrm{x}$ & & & & \\
\hline \multicolumn{7}{|l|}{ Extrinsic MOTIVES } \\
\hline Career (job opportunity, network etc.) & $\mathrm{x}$ & $\mathrm{x}$ & $\mathrm{x}$ & & $\mathrm{x}$ & $\mathrm{x}$ \\
\hline $\begin{array}{l}\text { Project goal [for ex: Provision of free } \\
\text { (geographical) data to the community] }\end{array}$ & $\mathrm{x}$ & & & & & $\mathrm{x}$ \\
\hline $\begin{array}{l}\text { Social motives (get into contact with } \\
\text { friends etc.), strengthen social relations }\end{array}$ & & & $x$ & & $\mathrm{x}$ & \\
\hline
\end{tabular}

\subsection{Contributory Mechanisms}

Comparing the platforms regarding their norms/rules-in-use OSM and WP provide the highest independence for their community. In these platforms rules and content are established in a bottom-up process, shaped by the community itself. Also FSQ house rules are set up by the community. All the other platforms have pre-defined, set up rules.

Furthermore, we analysed software tools of the different platforms for contributing information to the community. Results show, that OSM offers the most complex tools. Contributors may use - additional to its web editor Potlach - offline editors such as the Java OpenStreetMap Editor (JOSM), Merkaartor or Osmosis. They have to be installed as desktop applications, but provide higher functionality (e.g. adding properties beyond the standard, creating new tags etc.). All other platforms (GMM, FSQ, PAN, FB, WP) do not require any specific software; thus, users can contribute data easily through web and/or mobile applications.

Finally, the platforms propose various communication tools to allow contributors to interact with each other. Analysis reveals that there are rather small differences. All platforms provide mailing lists, blogs, e-mail, discussion forums, help forums and contests. Also, events for community meetings take place within all platforms, except of WP. Voice calling is exclusively offered by FB. A Wiki function is provided by OSM, GMM, FB and WP. Chat is possible within OSM, FSQ and FB. However, the major difference between the platforms is their use of communication tools. Results show that OSM users mainly communicate over mailing lists, whereas GMM users are predominately active in discussion forums. In contrast, the WP community predominantly interacts with each other via talk pages (e.g. for reaching consensus about the contents of articles). 


\subsection{Contributions}

When investigating the different kinds of data contribution, analysis shows that contributors of spatially explicit platforms primarily interact for sharing knowledge about the contribution. Communication content is predominately related to geospatial information and not to sharing personal information. As OSM and GMM aim at creating geospatial data, the platforms require certain expert knowledge from its contributors. Particularly, they must have know-how about the nature and structure of geo data (points, lines, shapes, and tagging schemes) in order to contribute data. A similar case is WP which requires from its users to be proficient in the topic they like to contribute to and also in Wiki language (KUZNETSOV 2006). Referring to the other UGC projects FB, FSQ and PAN, they do not require special knowledge in order to contribute to the platform. For instance, in FB viewing and commenting on other people's content as well as sending messages to each other represents a main part of data contribution on this platform.

\section{Discussion and Further Work}

In this paper, we have compared spatially explicit, spatially implicit and non-spatial UGC platforms in order to identify individual, social and technological factors that are linked to the unequal number of female contributors in spatially explicit UGC platforms. Concerning our first research question "Is gender participation imbalance a phenomenon of UGC in general or is the spatial aspect a critical point for participation/non-participation?", results of our cross-case study analysis indicate that gender participation imbalance is not a common problem of UGC, neither is it directly linked with spatial geographical content creation or consumption. For instance, FSQ as an example of a spatially implicit UGC project counts $60 \%$ of female contributors, whereas the non-spatial platform FB has also about $53 \%$. However, the percentage of female participants in WP which represents a non-spatial platform, too, is quite low $(9 \%)$.

This led us to our second question "Which criteria influence gender participation imbalance in spatially explicit, implicit and non-spatial UGC projects?" which will be discussed according to the three main arenas (motivations, contributory mechanism and contribution) of our applied conceptual framework (see section 3). Summarising outcomes regarding motivations, results show that social motives may be the most influential factors on gender imbalance in UGC platforms. OSM and GMM which are the platforms hardly contributed to by females (OSM 3\%, GMM 2\%) both lack social aspects. WP as a non-spatial platform does not have these motivators either and records only $9 \%$ of female contributors. In contrast, for FB and FSQ where amongst others social reasons are motives for participation, women participation is higher (FSQ 40\%, FB 53\%). Concerning contributory mechanisms, analysis shows that platforms with very stringent rules have the highest number of female contributors, whereas OSM and WP, with the most flexible frameworks for rules and norms, count small numbers of female contributors. Furthermore, results reveal that platforms allowing to control their communication such as deleting or disallowing comments as well as choosing who can read and contribute (HERRING 2011) (e.g. FB, FSQ) have a higher participation of women than those platforms mainly using open forms of communication in the community such as mailing lists or discussion forums (e.g. OSM, GMM, WP). Finally, relating to data contribution, analysis shows that those platforms with the 
strongest focus on sharing personal information and interacting with other members from the community (FB and FSQ) reveal the best balance of male and female contributors. Those platforms with limited (e.g. PAN) or without the option of at least commenting on other people's contributions (OSM, GMM and WP) count the lowest numbers of female contributors.

Thus, while we can conclude that the spatial aspect does not seem to be the critical point for non-participation in VGI projects, social motives as well as platform-specific contribution and communication mechanisms influence women's participation behaviour. However, the cross-case analysis presented in this paper is considered only a first step towards a more indepth analysis of why gendered contributions have a minority in VGI projects. More research, including quantitative (e.g. searching for correlations between specific criteria) and qualitative studies (interviews, surveys, focus groups) is needed to analyse the underlying reasons for the problems revealed by our findings, and to determine what can be done to improve the situation.

\section{References}

Boulton, A. (2010), Just maps, Google's Democratic Map-Making Community. Cartographica, 45 (1), 1-4.

Brando, C. \& Bucher, B. (2010), Quality in User Generated Spatial Content: A Matter of Specifications. AGILE International Conference on Geographic Information Science 2010, Guimaraes Portugal, 1-8.

Budhathoki, N. R., Nedović-Budić, Z. \& Bruce, B. C. (2010), An interdisciplinary frame for understanding Volunteered Geographic Information. Geomatica, 64 (1), 11-26.

Coleman, D. J., Geogiadou, Y. \& Labonte, J. (2009), Volunteered Geographic Information: The Nature and Motivation of Producers. International Journal of Spatial Data Infrastructures Research, 4, 332-358.

Devers, K. J. \& Frankel, R. M. (2000), Study Design in Qualitative Research - 2: Sampling and Data Collection Strategies. Education for Health, 1 (2), 263-271.

Elwood, S., GoODCHILD, M. \& SUI, D. (2012), Researching volunteered geographic information (VGI): Spatial data, geographic research, and new social practice. Annals of the Association of American Geographers, 102 (3), 571-590.

Gerlach, J. (2010), Vernacular Mapping, and the Ethics of What Comes Next. Cartographica, 45 (3), 165-168.

Glott R., Schmidt, P. \& Gosh, R. (2010), Wikipedia Survey - Overview of Results, United Nations University, UNU-MERIT, Collaborative Creativity Group.

http://www.wikipediasurvey.org/docs/Wikipedia_Overview_15March2010-FINAL.pdf (2012/10/12).

GoodCHILD, M. F. (2007), Citizens as sensors: the world of volunteered geography. GeoJournal, 69 (4), 211-221.

HAKLAY, M. \& BudHATHOKI, N. (2010), OpenStreetMap - Overview and Motivational Factors, Horizon Infrastructure Challenge Theme Day. The University of Nottingham.

HAKLAY M., BUDHATHOKI N. \& ANTONIOU, V. (2010), The tyranny of place.

http://povesham.wordpress.com/?s=spatially+explicit (14/09/2012). 
HERRING S. (2011), A difference of communication styles. New York Times Article. http://www.nytimes.com/2011/01/31/business/media/31link.html?_r=2\&ref=women (2011/01/30).

IgNite Social Media (2011), Social Network Analysis Data. https://s3.amazonaws.com/ignitesma/ignitewebsite/2011-social-network-analysis.pdf.

KuZNETSOV S. (2006), Motivations of contributors to Wikipedia. ACM SIGCAS Computers and Society, 36 (2), New York.

LECHNER M. (2011), Nutzungspotentiale crowdsource-erhobener Geodaten auf verschiedenen Skalen. Dissertation, Universität Freiburg.

NedoviĆ-Budić, Z. \& BudHATHOKI, N. (2010), Motives for VGI Participants, presentation at the VGI for SDI Workshop 16 April 2010, Wageningen University. http://ncg.knaw.nl/Studiedagen/10VGIforSDI/presentaties/Zorica_Nama_VGI_for_SDI. pdf.

Nov, O. (2007), What motivates Wikipedians? Communications of the ACM, 50 (11).

RAK, A., ColEmAn, D. \& NichOls, S. (2012), Legal liability concerns surrounding Volunteered Geographic Information applicable to Canada. In: RAJABIFARD, A. \& COLEMAN, D. (Eds.), Spatially Enabling Government, Industry and Citizens: Research and Development Perspectives, 125-142. GSDI Association Press.

RAmM, F. \& Topf, J. (2010), OpenStreetMap ( $3^{\text {rd }}$ ed.), Die freie Weltkarte nutzen und mitgestalten. Berlin, lehmanns media.

Rehrl, K., Gröchenig, S., Hochmair, H., Leitinger, S., Steinmann, R. \& Wagner, A. (2012), A conceptual model for analyzing contribution patterns in the context of VGI. In: LBS $2012-9^{\text {th }}$ Symposium on Location Based Services. Berlin, Springer.

Ross, C., Orr, E. S., Arseneault, J. M., Simmering, M. G. \& OrR, R. (2009), Personality and motivations associated with Facebook use. Computers in Human Behavior, 25, 578586.

STARK, H. J. (2010), Empirische Untersuchung der Motivation von Teilnehmenden bei der freiwilligen Erfassung von Geodaten, Fachhochschule Nordwestschweiz, Presentation.

StePHENS, M. \& RondinOne A. (2012), Gendering the GeoWeb, presentation at annual meeting 24-28.02. 2012, New York. http://www.scoop.it/t/opensource-geo/p/1452578643/gendering-the-geoweb-analysingdemographic-difference-in-usvgi.

Uhlmann J., TOMmasini, F. \& StaRk H. J. (2010), Empirische Untersuchung der Motivation von Teilnehmern bei der freiwilligen Erfassung von Geodaten. Presentation at FOSSGIS 2010.

VALENTINO-DeVRIES, J. (2011), Where the young and tech-savy go, The Wallstreet Journal Blog, May 10th 2011. http://blogs.wsj.com/digits/2011/05/19/a-week-on-foursquare/.

WIKIPEDIA EDITORS STUDY (2011), Results from the editor survey. http://commons.wikimedia.org/wiki/File:Editor_Survey_Report_-_April_2011.pdf (2012/10/04).

YANG H. L. \& LAI, C. Y. (2010), Motivations of Wikipedia content contributors. Computers in Human Behaviour, 26, 1377-1383. 